\title{
Procalcitonin and Liver Disease: A Literature Review
}

\author{
Ruolin Dong ${ }^{1}$, Bo Wan ${ }^{2}$, Su Lin², Mingfang Wang ${ }^{2}$, Jiaofeng Huang ${ }^{2}$, Yinlian $\mathrm{Wu}^{2}$, Yilong $\mathrm{Wu}^{2}$, \\ Nanwen Zhang ${ }^{3}$ and Yueyong Zhu*1
}

${ }^{1}$ The First Affiliated Hospital of Fujian Medical University, Fuzhou, China; ${ }^{2}$ Liver Research Center, The First Affiliated Hospital of Fujian Medical University, Fuzhou, China; ${ }^{3}$ Department of Pharmacology, School of Pharmacy, Fujian Medical University, Fuzhou, China

\begin{abstract}
Procalcitonin (PCT) is a widely used biomarker for the diagnosis of bacterial infections. It is produced by various organs and the liver is considered to be the most important site of production. Severe liver dysfunction has been shown to influence PCT levels. Patients with no sources of infection who have liver disease are observed to have increased serum levels of PCT, thereby reducing the diagnostic utility and value within this particular patient subset. Here, we have summarized the relationship between PCT and liver disease, including liver cirrhosis, liver failure, and liver transplantation.
\end{abstract}

Citation of this article: Dong $R$, Wan $B$, Lin $S$, Wang $M_{\text {, }}$ Huang J, Wu $Y$, et al. Procalcitonin and liver disease: A literature review. J Clin Transl Hepatol 2019;7(1):51-55. doi: 10.14218/JCTH.2018.00012.

\section{Introduction}

Procalcitonin (PCT) is a widely used biomarker for the diagnosis of bacterial infections. ${ }^{1}$ It is produced by thyroid $\mathrm{C}$ cells, with very low concentration $(<0.05 \mathrm{ng} / \mathrm{mL})$ in the blood of healthy individuals under normal physical conditions. ${ }^{2}$ During an inflammatory response, however, and especially those induced by bacterial infections, various tissues and cells can produce and release PCT into the bloodstream.

Serum PCT level increases during bacterial infections but usually remains low during viral infections and nonspecific inflammatory diseases. As such, serum PCT is recognized to be an important biomarker for bacterial infections. For example, PCT has diagnostic value for bacterial infections in advanced liver disease and spontaneous bacterial peritonitis (SBP). Recent studies have shown that the concentration of PCT can reflect hepatocellular injury and that the severity of liver disease might also influence the diagnostic value of PCT for infections. ${ }^{3}$

Keywords: Procalcitonin; Liver disease; Infection.

Abbreviations: ALF, acute liver failure; CRP, C-reactive protein; DAMPs, damage-associated molecular patterns; IL, interleukin; MELD, model for endstage liver disease; $\mathrm{PCT}$, procalcitonin; SBP, spontaneous bacterial peritonitis; SIRS, systemic inflammatory response syndrome; TBIL, total bilirubin; TNF, tumor necrosis factor.

Received: 20 February 2018; Revised: 2 September 2018; Accepted: 23 October 2018

*Correspondence to: Yueyong Zhu, Liver Research Center, The First Affiliated Hospital of Fujian Medical University, Fuzhou 350005, China. Tel: +86-59187981660, Fax: +86-591-83356180, E-mail: zhuyueyong@fjmu.edu.cn
The findings from recent studies have been summarized below.

Severe liver diseases and PCT

\section{PCT production}

Initially, high levels of PCT were observed in thyroid surgery patients, which drove a common consensus that the synthesis of PCT took place in thyroid tissues. ${ }^{4}$ Later, it was discovered in a baboon model of septic shock that PCT production was almost undetectable when the liver was resected, indicating that the liver was the main source of PCT during infection. ${ }^{5}$ Various tissues, including the liver, lungs, kidneys, adrenal glands, prostate gland, small intestines and testes as well as peripheral blood mononuclear cells and granulocytes, have been shown to produce PCT. However, the liver is still the most significant site of PCT production.

During the early stages of proinflammatory conditions, PCT is secreted by cytokine-activated macrophages while interacting with endothelial cells. ${ }^{6}$ Driven by a sustained concentration of proinflammatory mediators in the blood, further PCT production and release are initiated in the parenchyma of a variety of organs, resulting in a 10,000 - to 100,000 -fold increase of PCT plasma concentration. ${ }^{7}$

\section{PCT levels in advanced liver diseases}

Theoretically, liver diseases should affect the synthesis of PCT and therafter decline its production in blood concentration. However, clinical observations have revealed that serum PCT levels of patients with steatohepatitis and simple steatosis were similar to control groups. ${ }^{8}$ However, in patients with advanced liver diseases, baseline PCT levels were observed to rise even when bacterial infections were absent, suggesting a more complex relationship between liver and PCT. Serum PCT levels were also reportedly higher in uncomplicated cirrhosis patients without established bacterial infection, regardless of the causes and the severity of cirrhosis. ${ }^{9}$

Rule et al. ${ }^{10}$ found that PCT values from patients with chronic liver disease $(0.104 \mathrm{ng} / \mathrm{mL})$ significantly differed from those in patients with acute liver failure (ALF) $(2.0 \mathrm{ng} / \mathrm{mL})$. And, the PCT concentrations in most ALF patients were near or above a cut-off that generally indicates severe sepsis. Sugihara et al. ${ }^{11}$ also discovered that serum PCT levels were significantly higher in patients with ALF compared to patients with non-ALF $(0.25(0.13-2.66) \mathrm{ng} / \mathrm{mL}$ vs. $0.165(0.03-1.08)$ $\mathrm{ng} / \mathrm{mL}, p<0.01)$. They suggested that with a PCT cut-off 
value of $0.5 \mathrm{ng} / \mathrm{mL}$, ALF could be demonstrated to be present with low sensitivity $(37.5 \%)$, high specificity $(96.5 \%)$ and high positive $(85.7 \%)$ and negative $(72.9 \%)$ predictive value.

PCT levels in liver transplant patients also exhibit dynamic changes. Generally, it shows an initial rise before falling gradually and usually takes 7 days post-surgery to reach a low level of PCT. ${ }^{12,13}$ In fact, it is not uncommon to observe an increase in PCT levels in patients with noninfectious diseases. Such observations are usually made in cases of more critical diseases, such as acute ischemic stroke ${ }^{14}$ and congestive heart failure. ${ }^{15}$ From the aforementioned studies, it is shown that in patients without infectious liver disease, a raised PCT is only seen in advanced liver diseases, such as in liver failure and decompensated liver cirrhosis.

\section{Causes for PCT level increase}

There are several potential causes for increases in PCT levels observed in patients with advanced liver disease (Fig. 1).

Endotoxin: Endotoxin, a lipopolysaccharide present in the outer cell membrane of Gram-negative bacteria, can be recognized by the host Toll-like receptor 4 , a transmembrane receptor expressed in different immune cells, such as neutrophils, monocytes, macrophages, and dendritic cells. ${ }^{16}$ On activation, these cells produce inflammatory mediators (e.g., the tumor necrosis factor (TNF) and interleukin (IL)1beta, IL-6, IL-8, IL-10), which leads to the induction of a variety of inflammatory processes. ${ }^{17,18}$ During the early stages of proinflammatory conditions, PCT is secreted by

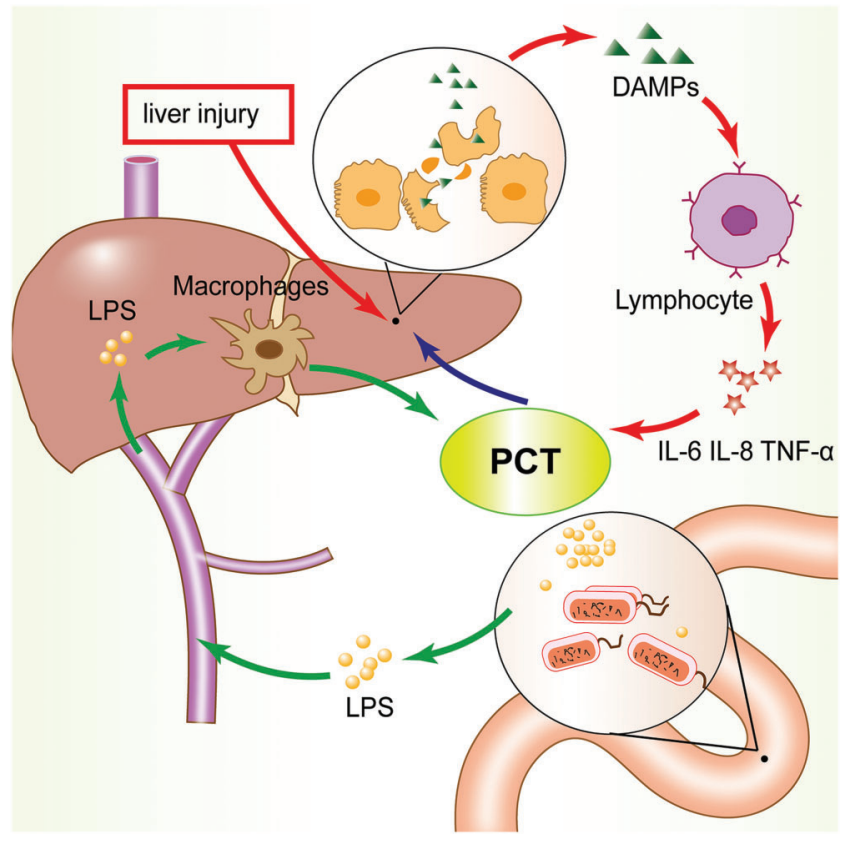

Fig. 1. Possible pathophysiological mechanisms of the relationship between PCT and liver damage. Endotoxin: The endotoxins are directly released into the circulation through the small intestines and the colon, raising blood concentration levels and resulting in the synthesis of a large amount of PCT. DAMPs: Liver injury results in the death of a vast amount of liver cells, releasing DAMPs. DAMPs, through sensors and effector cells, release IL-6, IL- 8 and TNF- $\alpha$, that can induce the expression of PCT. The vicious cycle of PCT and liver cell damage: A rise in PCT accelerates cell damage and results in a vicious cycle. Abbreviations: DAMPs, damage-associated molecular patterns; IL, interleukin; PCT, procalcitonin; TNF, tumor necrosis factor. cytokine-activated macrophages while interacting with endothelial cells. ${ }^{6}$

In patients with liver transplantation, during the anhepatic phase, endotoxins are directly released into the circulation through the small intestines and the colon, raising blood concentration levels. At the same time, the liver's capability to eliminate endotoxins is reduced after the transplant, resulting in the synthesis of a large amount of PCT. ${ }^{13,19,20}$ Due to damage of the intestinal barrier, patients with cirrhosis and liver failure also suffer from endotoxemia, which may then result in increased synthesis of PCT.

Damage-associated molecular patterns (DAMPs): DAMPs are a range of intracellular molecules with immunomodulatory activity. Liver injury results in the death of a vast amount of liver cells, releasing DAMPs in the process. In return, DAMPs, through sensors and effector cells, release mediators and biomarkers with impact on liver function. The process is not specific to the liver. ${ }^{21}$ Other organs like brain, lung and kidney, and systems like cardiovascular, gut and micro-circulation, release DAMPs and are also affected by such. The DAMPs induce autoimmunity or immune tolerance through the pattern recognition receptor ${ }^{21,22}$ and share the same sensors and effector cells as pathogen-associated molecular patterns. The activation of the downstream pathway of DAMPs/pathogen-associated molecular patterns may cause systemic inflammation. ${ }^{21}$

High levels of IL-6, IL-8, and TNF- $\alpha$ indicate the presence of systemic inflammation. ${ }^{23}$ Furthermore, a significant rise in IL-1 $\beta$ and TNF- $\alpha$ can induce the expression of PCT. ${ }^{24,25}$ Liver cell damage and inflammatory response may be the reason behind the positive correlation between PCT levels and severity of liver diseases. This can partially explain the mechanism behind the increased PCT levels in patients with liver failure.

The vicious cycle of PCT and liver cell damage: A rise in PCT also accelerates cell damage and results in a vicious cycle. Research by Sauer and Doss ${ }^{26}$ found that even a very low level of serum PCT (starting at $0.25 \mathrm{ng} / \mathrm{mL}$ ) can initiate a dose-dependent cell lysis, as evidenced by high and increasing levels of lactate dehydrogenase in cell culture supernatant (2.04 \pm 0.07 -fold vs. control, $p<0.001)$. The study also showed that PCT, in a dose-dependent manner, is capable of affecting all qualities of cellular functions, such as proliferation, induction of cell death, metabolism, integrity, microalbumin synthesis, and detoxification capacity to only half of that of control cells $(0.46 \pm 0.14$-fold vs. control for $0.01 \mathrm{ng} / \mathrm{mL}$, $p<0.001)$. This suggests that PCT may be responsible for inducing hepatocyte dysfunction and impairment of cellular integrity. In this way, as part of a vicious cycle of sterile inflammation and liver cell necrosis, PCT may self-propagate its own release into the systemic circulation, resulting in raised PCT levels in patients with advanced liver diseases.

\section{Application of PCT in liver diseases}

\section{PCT in predicting prognosis for advanced liver diseases}

Liver failure: Liver failure indicates severe liver damage and can be caused by a variety of factors. It results in a severe disorder or decompensation in functions, such as synthesis, detoxification, excretion, and bioconversion, leading to a clinical syndrome which can include coagulopathy, jaundice, hepatic encephalopathy and ascites. ${ }^{27}$ The severity of liver failure is correlated with high mortality and thus it is 
important to identify biomarkers that will help predict prognosis in these patients.

Sugihara et al. ${ }^{11}$ found that the cumulative survival rate of patients with liver failure was significantly lower when serum PCT concentrations were $\geq 0.5 \mathrm{ng} / \mathrm{mL}$. However, PCT was not an independent prognostic factor. Creatinine $\geq 175 \mu \mathrm{mol} / \mathrm{L}$, C-reactive protein (CRP) $\geq 25 \mathrm{mg} / \mathrm{L}$, multisite infection, acute-on-chronic liver failure, and advanced hepatocellular carcinoma were also identified as independent predictors of 90-day mortality in cirrhotic patients with systemic inflammatory response syndrome (commonly known as SIRS). Similarly, another study also demonstrated that a procalcitonin level of $\geq 1.0 \mathrm{ng} / \mathrm{mL}$ can predict the 90 -day mortality rate for liver cirrhosis, but only in univariate analysis. ${ }^{28}$

If combined with other markers (i.e. peripheral blood neutrophil, lymphocyte ratio, model for end-stage liver disease (MELD) score, and age), the prognostic value of PCT for liver failure can be improved. Zhou et al. ${ }^{29}$ found that both age and PCT are positively correlated with MELD scores (i.e. the older the patient, the more concentrated the PCT level and hence a higher MELD score and a higher risk of death). The specificity of the MELD score combined with PCT was $100 \%$, and the positive prediction value was 1.00 . PCT also significantly predicted the 90-day survival rate for alcoholic hepatitis. Specifically, the 90 -day mortality rate of patients with PCT levels $<0.6 \mathrm{ng} / \mathrm{mL}$ was $14.9 \%$ versus $60 \%$ in patients with PCT levels $\geq 0.6 \mathrm{ng} / \mathrm{mL}(p<0.001){ }^{30}$

However, there are still few studies exploring the relationship between PCT and the prognosis for liver failure. Since a significant increase of PCT levels in patients with liver failure may be related to the DAMPs and inflammatory mediators released after liver damage, PCT may prove a useful biomarker for liver damage. More studies are needed to investigate the value of PCT as a prognostic indicator in patients with liver failure.

Liver transplantation: As for liver transplantation, the survival rate of patients with early post-transplant sepsis is generally low. One study indicated that higher rates of sepsis are correlated with patients who have a pretransplant serum PCT level of $>0.5 \mathrm{ng} / \mathrm{mL}$. Therefore, researchers have suggested re-evaluating patient fitness and postponing liver transplant in patients with a pretransplant serum PCT level of $>0.5 \mathrm{ng} / \mathrm{mL}^{31}$

\section{PCT as a diagnostic biomarker}

Patients with the severe liver disease are prone to having bacterial infections, but often lack significant symptoms in the early stage of infection. Common inflammatory indicators such as white blood cells and neutrophils are easily affected by hypersplenism ${ }^{32}$ and so their diagnostic value is limited. There is an urgent need to identify more sensitive biomarkers for diagnosis in this population. PCT is used for the diagnosis of various bacterial infections, such as pneumonia, sepsis, septic shock, and blood infections. However, no agreeable consensus has been made on its clinical value for liver diseases with bacterial infections.

Some scholars have acknowledged the diagnostic value of PCT for bacterial infections in advanced liver disease. Bota et al. ${ }^{33}$ believe that PCT levels do not differ noticeably between patients with and without cirrhosis and are not related to the severity of cirrhosis. According to research carried out in 2015 among SIRS patients, PCT levels were observed to be higher in those with infection $(0.89 \mathrm{ng} / \mathrm{mL})$ than those without infection $(0.35 \mathrm{ng} / \mathrm{mL})$; the cut-off value to rule out infections was $0.25 \mathrm{ng} / \mathrm{mL} .{ }^{30}$ Another study also confirmed the diagnostic value of PCT for infection in alcoholic hepatitis. In that research, the authors found that a cut-off value of $0.57 \mathrm{ng} / \mathrm{mL}$ performed well (with a sensitivity of $79 \%$ and specificity at $82 \%$ ) in the diagnosis of sepsis. ${ }^{34} \mathrm{~A}$ metaanalysis also drew the same conclusions, claiming that PCT is better than CRP in differentiating the causes of infections and systemic inflammatory response. ${ }^{35}$

The diagnostic value of PCT for SBP has been well studied. Cekin et al. ${ }^{36}$ demonstrated that serum PCT levels were positively correlated with the severity of SBP, and PCT performed better than traditional inflammatory biomarkers, such as CRP, in the prediction of SBP. ${ }^{36} \mathrm{~A}$ cohort from China consisting of 88 advanced cirrhotic patients compared PCT and CRP as diagnostic markers for SBP. The serum CRP levels could not efficiently differentiate patients with SBP from the noninfected controls. However, with a cut-off value of $>0.78 \mathrm{ng} / \mathrm{mL}$, PCT was shown to be a good predictor of SBP, with a sensitivity and specificity of $77.5 \%$ and $60.4 \%$ respectively.

From these findings, serum PCT levels appear to accurately diagnose SBP in advanced cirrhotic patients. ${ }^{37} \mathrm{~A}$ later meta-analysis that included 7 studies and 742 suspected cases of SBP found the following: the 339 confirmed cases of SBP showed that, for the diagnosis of SBP, PCT had a sensitivity of 0.82 and a specificity of 0.86 , with an area under the curve of $0.92 .^{38}$ Thus, with high positive predictive value and high clinical suspicion, serum PCT can be a relatively sensitive and specific biomarker to help diagnose SBP.

When combined with other biomarkers for infection, PCT can help make a more accurate diagnosis. Cai et al. ${ }^{39}$ have found serum PCT levels to be a satisfactory early diagnostic biomarker for infection in patients with decompensated liver cirrhosis with ascites. For the combined PCT and white blood cell/platelet measurements, the sensitivity was $76.8 \%$ and $83.6 \%$ for the diagnosis of infections or SBP in decompensated liver cirrhotic patients with ascites, respectively. A combination of PCT and ascitic albumin also helps improve the diagnostic accuracy for SBP. ${ }^{40}$

In liver transplant patients, although PCT exhibits dynamic changes, Kaido et al. ${ }^{41}$ discovered that a PCT level $>2 \mathrm{ng} / \mathrm{mL}$ and $<0.5 \mathrm{ng} / \mathrm{mL}$ can be used to diagnose or rule-out bacteremia. Hence, identifying a suitable threshold and monitoring serum PCT dynamically can contribute to a faster diagnosis of severe infections after liver transplant. Gur et al. ${ }^{42}$ drew a similar conclusion. Another article pointed out that the only independent risk factor for post-transplant sepsis is pretransplant PCT levels of $>0.5 \mathrm{ng} / \mathrm{mL} .{ }^{31}$ Hence, some have suggested the use of serial PCT measurements, which may be more reliable than a single measurement in guiding early treatments for infection after organ transplantations. ${ }^{43}$

\section{Limitations of PCT as a biomarker}

Some scholars consider the diagnostic value of PCT for infections in cirrhotic patients no better than that of other inflammatory indicators, such as CRP and IL-6. Lin et al. ${ }^{44}$ claimed that, among cirrhotic patients, the diagnostic value of PCT is lower than IL-6 (for an IL- 6 cut-off value of $\geq 135 \mathrm{pg} / \mathrm{mL}$ ). For the diagnosis of bacterial infections during the early stages of fever, it was shown that IL- 6 has a sensitivity of $94.5 \%$ and a specificity of $93.7 \%$, which are significantly higher than that of PCT. Hamed et al. ${ }^{45}$ discovered that when the cut-off value for CRP is set at $10.5 \mathrm{ng} / \mathrm{mL}$, the 
sensitivity and specificity for the diagnosis of infection in patients with liver disease are $91 \%$ and $97 \%$ respectively, higher than that of PCT (cut-off value: $495 \mathrm{pg} / \mathrm{mL}$, sensitivity: $90 \%$, specificity: $92 \%$ ). Wang et al. ${ }^{46}$ also drew a similar conclusion, showing that a cut-off value of $0.59 \mu \mathrm{g} / \mathrm{mL}$ for PCT concentrations in patients during the early stages of liver cirrhosis yielded a sensitivity of only at $61.7 \%$ and a high cost to benefit ratio for the diagnosis of infection.

In comparison, IL-6 has a higher sensitivity and a lower cost-to-benefit ratio and its incremental cost-effectiveness ratio is also significantly lower than that of PCT. As a result, IL- 6 is considered to be more economical and a better indicator of bacterial infections during the early stages of fever in cirrhotic patients. PCT is also an unsatisfactory biomarker for sepsis during the early phase following liver transplantation, whilst IL- 6 performs much better for detecting postoperative bacterial sepsis. ${ }^{47}$

From the above studies, it can be observed that the PCT thresholds for diagnosis of infections in most studies concerning patients with liver diseases are at least $0.5 \mathrm{ng} / \mathrm{mL}$. This value is 10 -times the normal threshold. This raises a new question on whether the threshold needs to be raised when diagnosing infections in a population of patients with liver diseases.

Qu et al. ${ }^{3}$ have discovered a positive correlation between serum PCT and serum total bilirubin (TBIL) level and suggested the diagnostic threshold should be adjusted according to the stages of liver function. Serum TBIL affects the threshold of PCT, as a result, the diagnostic cut-offs of PCT require adjustment according to the state of liver function: when TBIL is $<5 \mathrm{mg} / \mathrm{mL}$, the optimum threshold for predicting bacterial infections is $0.38 \mathrm{ng} / \mathrm{mL}$; when TBIL is equal to or greater than $5 \mathrm{mg} / \mathrm{mL}$ but under $10 \mathrm{mg} / \mathrm{mL}$, the optimum threshold for PCT is $0.54 \mathrm{ng} / \mathrm{mL}$; and, when TBIL is between 10 and $20 \mathrm{mg} / \mathrm{mL}$ or above $20 \mathrm{mg} / \mathrm{mL}$, the thresholds for PCT are $0.61 \mathrm{ng} / \mathrm{mL}$ and $0.94 \mathrm{ng} / \mathrm{mL}$, respectively. However, further clinical studies are required to confirm this conclusion.

There are also a number of scholars who deny the diagnostic value of PCT for infections in ALF patients. For instance, Rule et al. ${ }^{10}$ believe that, in ALF patients, severe necrosis accompanying infections is the cause of the increase of PCT level and that PCT is very poor at picking up nonbacterial infections in ALF patients. Mallet et al. ${ }^{48}$ suggest that the diagnostic value of PCT for infections in patients with liver failure is related to the cause of disease.

At present, there is still much need for more research with regards to the application of PCT as a diagnostic marker for infection in patients with liver disease. Serial PCT measurements during the first week following liver transplantation are not effective in identifying bacterial infections in patients. Instead, PCT is proposed to be a more useful indicator to use after the first week of liver transplantation. ${ }^{12}$

\section{Conclusions}

In summary, although PCT is an efficient biomarker for the diagnosis of infections among the general population, this is not the case for patients with severe liver disease, including liver cirrhosis, liver failure, and liver transplantation. In this group of patients, its diagnostic thresholds and effectiveness need to be reconsidered. PCT alone may not be effective enough to predict the presence of bacterial infections, but combining it with other biomarkers may increase diagnostic value.
A meta-analysis has demonstrated that using PCT to guide the initiation and duration of antibiotic treatments leads to lower mortality risks, reduced antibiotic use and lower risks of antibiotic-related side effects. ${ }^{49}$ However, whether PCT carries the same instructive value for the use of antibiotics when treating infection in patients with liver disease requires further exploration. As a result, when making the diagnosis of infections using PCT, it is essential to take into consideration other clinical features and indicators before reaching any clinical decisions. The prognostic value of PCT for liver diseases also requires further exploration.

\section{Acknowledgments}

This study was funded by the Fujian Medical Innovation Project (2016-cx-033), the Pilot Project of Fujian Science and Technology Department (2016Y0040, 2017J01187) and the Fujian Natural Science Foundation (2017j01187).

\section{Conflict of interest}

The authors have no conflict of interests related to this publication.

\section{Author contributions}

Writing of the paper (RD, BW), data collection (RD, $Y Z, S L$ ) and conception of the study and review of the final paper (MW, JH, YW, YW, NZ, YZ).

\section{References}

[1] Vijayan AL, Vanimaya, Ravindran S, Saikant R, Lakshmi S, Kartik R, et al. Procalcitonin: a promising diagnostic marker for sepsis and antibiotic therapy. J Intensive Care 2017;5:51. doi: 10.1186/s40560-017-0246-8.

[2] Gómez-Cerquera JM, Daroca-Pérez R, Baeza-Trinidad R, Casañas-Martinez M, Mosquera-Lozano JD, Ramalle-Gómara E. Validity of procalcitonin for the diagnosis of bacterial infection in elderly patients. Enferm Infecc Microbiol Clin 2015;33:521-524. doi: 10.1016/j.eimc.2014.10.019.

[3] Qu J, Feng P, Luo Y, Lü X. Impact of hepatic function on serum procalcitonin for the diagnosis of bacterial infections in patients with chronic liver disease: A retrospective analysis of 324 cases. Medicine (Baltimore) 2016;95:e4270 doi: $10.1097 / M D .0000000000004270$.

[4] Nishikura T. Procalcitonin (PCT) production in a thyroidectomized patient Intensive Care Med 1999;25:1031. doi: 10.1007/s001340051006.

[5] Meisner M, Müller V, Khakpour Z, Toegel E, Redl H. Induction of procalcitonin and proinflammatory cytokines in an anhepatic baboon endotoxin shock model. Shock 2003;19:187-190. doi: 10.1097/00024382-20030200000017.

[6] Linscheid P, Seboek D, Schaer DJ, Zulewski H, Keller U, Müller B. Expression and secretion of procalcitonin and calcitonin gene-related peptide by adherent monocytes and by macrophage-activated adipocytes. Crit Care Med 2004;32:1715-1721. doi: 10.1097/01.ccm.0000134404.63292.71.

[7] Russwurm S, Stonans I, Stonane E, Wiederhold M, Luber A, Zipfel PF, et al. Procalcitonin and CGRP-1 mrna expression in various human tissues. Shock 2001;16:109-112. doi: 10.1097/00024382-200116020-00004.

[8] Oruc N, Ozutemiz O, Yuce G, Akarca US, Ersoz G, Gunsar F, et al. Serum procalcitonin and CRP levels in non-alcoholic fatty liver disease: a case control study. BMC Gastroenterol 2009;9:16. doi: 10.1186/1471-230X-916.

[9] Elefsiniotis IS, Skounakis M, Vezali E, Pantazis KD, Petrocheilou A, Pirounaki $M$, et al. Clinical significance of serum procalcitonin levels in patients with acute or chronic liver disease. Eur ] Gastroenterol Hepatol 2006;18:525530. doi: 10.1097/00042737-200605000-00012.

[10] Rule JA, Hynan LS, Attar N, Sanders C, Korzun WJ, Lee WM. Procalcitonin identifies cell injury, not bacterial infection, in acute liver failure. PLoS One 2015;10:e0138566. doi: 10.1371/journal.pone.0138566.

[11] Sugihara T, Koda M, Okamoto T, Miyoshi K, Matono T, Oyama K, et al. Serum procalcitonin in patients with acute liver failure. Yonago Acta Med 2017;60: 40-46. 
[12] Cousin VL, Lambert K, Trabelsi S, Galetto-Lacour A, Posfay-Barbe KM, Wildhaber $\mathrm{BE}$, et al. Procalcitonin for infections in the first week after pediatric liver transplantation. BMC Infect Dis 2017;17:149. doi: 10. 1186/s12879-017-2234-y.

[13] Fazakas J, Gondos T, Varga M, Sarvary E, Horovitz P, Perner F. Analysis of systemic and regional procalcitonin serum levels during liver transplantation. Transpl Int 2003;16:465-470. doi: 10.1007/s00147-002-0512-z.

[14] Tian D, Zhang S, He X, Liu H. Serum procalcitonin as a diagnostic marker in acute ischemic stroke. Neuroreport 2015;26:33-37. doi: 10.1097/WNR. 0000000000000298.

[15] Canbay A, Celebi OO, Celebi S, Aydogdu S, Diker E. Procalcitonin: a marker of heart failure. Acta Cardiol 2015;70:473-478. doi: 10.1080/ac.70.4. 3096896.

[16] Akira S, Uematsu S, Takeuchi O. Pathogen recognition and innate immunity. Cell 2006;124:783-801. doi: 10.1016/j.cell.2006.02.015.

[17] van Deventer S], Büller HR, ten Cate JW, Aarden LA, Hack CE, Sturk A. Experimental endotoxemia in humans: analysis of cytokine release and coagulation, fibrinolytic, and complement pathways. Blood 1990;76:2520-2526.

[18] Cunningham PN, Dyanov HM, Park P, Wang J, Newell KA, Quigg RJ. Acute renal failure in endotoxemia is caused by TNF acting directly on TNF receptor-1 in kidney. J Immunol 2002;168:5817-5823. doi: 10.4049/jimmunol.168.11. 5817.

[19] Kretzschmar M, Krüger A, Schirrmeister W. Hepatic ischemia-reperfusion syndrome after partial liver resection (LR): hepatic venous oxygen saturation, enzyme pattern, reduced and oxidized glutathione, procalcitonin and interleukin-6. Exp Toxicol Pathol 2003;54:423-431. doi: 10.1078/09402993-00291.

[20] Kornberg A, Grube T, Wagner T, Voigt R, Homman M, Schotte U, et al. Differentiated therapy with prostaglandin E1 (alprostadil) after orthotopic liver transplantation: the usefulness of procalcitonin (PCT) and hepatic artery resistive index (RI) for the evaluation of early graft function and clinical course. Clin Chem Lab Med 2000;38:1177-1180. doi: 10.1515/CCLM.2000.182.

[21] Reinhart K, Bauer M, Riedemann NC, Hartog CS. New approaches to sepsis: molecular diagnostics and biomarkers. Clin Microbiol Rev 2012;25:609-634. doi: 10.1128/CMR.00016-12.

[22] Wenceslau CF, McCarthy CG, Szasz T, Spitler K, Goulopoulou S, Webb RC. Mitochondrial damage-associated molecular patterns and vascular function. Eur Heart J 2014;35:1172-1177. doi: 10.1093/eurheartj/ehu047.

[23] Clària ], Stauber RE, Coenraad MJ, Moreau R, Jalan R, Pavesi M, et al. Systemic inflammation in decompensated cirrhosis: Characterization and role in acute-on-chronic liver failure. Hepatology 2016;64:1249-1264. doi: 10. 1002/hep. 28740 .

[24] Whang KT, Vath SD, Becker KL, Snider RH, Nylen ES, Muller B, et al. Procalcitonin and proinflammatory cytokine in interactions in sepsis. Shock 1999; 12:268-273. doi: 10.1097/00024382-199910000-00004.

[25] Domenech VS, Nylen ES, White JC, Snider RH, Becker KL, Landmann R, et al. Calcitonin gene-related peptide expression in sepsis: postulation of microbial infection-specific response elements within the calcitonin I gene promoter. J Investig Med 2001;49:514-521. doi: 10.2310/6650.2001.33628.

[26] Sauer M, Doß S, Ehler J, Mencke T, Wagner NM. Procalcitonin impairs liver cell viability and function in vitro: A potential new mechanism of liver dysfunction and failure during sepsis? Biomed Res Int 2017;2017:6130725. doi: 10. $1155 / 2017 / 6130725$.

[27] Sarin SK, Kedarisetty CK, Abbas Z, Amarapurkar D, Bihari C, Chan AC, et al. Acute-on-chronic liver failure: consensus recommendations of the Asian Pacific Association for the Study of the Liver (APASL) 2014. Hepatol Int 2014;8:453-471. doi: 10.1007/s12072-014-9580-2.

[28] Yang D, Xie Y, Pan H, Huang Y, Dai Y, Tong Y, et al. Clinical characteristics and prognostic factors of liver cirrhosis patients with systemic inflammatory response syndrome. Hepatol Res 2017;47:1174-1185. doi: 10.1111/hepr. 12886.

[29] Zhou Q, Tan D, Yi Z, Zheng Y, Lu M. Prognostic value of procalcitonin, endotoxin and common inflammatory markers combining MELD score in patients with chronic severe hepatitis. Zhong Nan Da Xue Xue Bao Yi Xue Ban 2013; 38:388-394. doi: 10.3969/j.issn.1672-7347.2013.04.009.

[30] Michelena J, Altamirano J, Abraldes JG, Affò S, Morales-Ibanez O, SanchoBru $\mathrm{P}$, et al. Systemic inflammatory response and serum lipopolysaccharide levels predict multiple organ failure and death in alcoholic hepatitis. Hepatology 2015;62:762-772. doi: 10.1002/hep.27779.
[31] Hara T, Soyama A, Hidaka M, Natsuda K, Adachi T, Ono S, et al. Pretransplant serum procalcitonin level for prediction of early post-transplant sepsis in living donor liver transplantation. Hepatol Res 2018;48:383-390. doi: 10. 1111/hepr.13043.

[32] Fernández J, Gustot T. Management of bacterial infections in cirrhosis. J Hepatol 2012;56:S1-S12. doi: 10.1016/S0168-8278(12)60002-6.

[33] Bota DP, Van Nuffelen M, Zakariah AN, Vincent JL. Serum levels of C-reactive protein and procalcitonin in critically ill patients with cirrhosis of the liver. J Lab Clin Med 2005;146:347-351. doi: 10.1016/j.lab.2005.08.005.

[34] Kumar K, Mohindra S, Raj M, Choudhuri G. Procalcitonin as a marker of sepsis in alcoholic hepatitis. Hepatol Int 2014;8:436-442. doi: 10. 1007/s12072-014-9540-x.

[35] Lin KH, Wang FL, Wu MS, Jiang BY, Kao WL, Chao HY, et al. Serum procalcitonin and C-reactive protein levels as markers of bacterial infection in patients with liver cirrhosis: a systematic review and meta-analysis. Diagn Microbiol Infect Dis 2014;80:72-78. doi: 10.1016/j.diagmicrobio.2014.03. 029.

[36] Cekin Y, Cekin AH, Duman A, Yilmaz U, Yesil B, Yolcular BO. The role of serum procalcitonin levels in predicting ascitic fluid infection in hospitalized cirrhotic and non-cirrhotic patients. Int J Med Sci 2013;10:1367-1374. doi: 10. $7150 /$ ijms.6014

[37] Wu H, Chen L, Sun Y, Meng C, Hou W. The role of serum procalcitonin and C-reactive protein levels in predicting spontaneous bacterial peritonitis in patients with advanced liver cirrhosis. Pak J Med Sci 2016;32:1484-1488. doi: 10.12669/pjms.326.10995.

[38] Yang Y, Li L, Qu C, Zeng B, Liang S, Luo Z, et al. Diagnostic accuracy of serum procalcitonin for spontaneous bacterial peritonitis due to end-stage liver disease: A meta-analysis. Medicine (Baltimore) 2015;94:e2077. doi: 10. 1097/MD.0000000000002077.

[39] Cai ZH, Fan CL, Zheng JF, Zhang X, Zhao WM, Li B, et al. Measurement of serum procalcitonin levels for the early diagnosis of spontaneous bacterial peritonitis in patients with decompensated liver cirrhosis. BMC Infect Dis 2015;15:55. doi: 10.1186/s12879-015-0776-4.

[40] Abdel-Razik A, Mousa N, Elhammady D, Elhelaly R, Elzehery R, Elbaz S, et al. Ascitic fluid calprotectin and serum procalcitonin as accurate diagnostic markers for spontaneous bacterial peritonitis. Gut Liver 2016;10:624-631. doi: $10.5009 / \mathrm{gnl} 15120$.

[41] Kaido T, Ogawa K, Fujimoto Y, Mori A, Hatano E, Okajima H, et al. Perioperative changes of procalcitonin levels in patients undergoing liver transplantation. Transpl Infect Dis 2014;16:790-796. doi: 10.1111/tid.12282.

[42] Gür A, Oguzturk H, Köse A, Turtay MG, Ersan V, Bayindir Y, et al. Prognostic value of procalcitonin, CRP, serum amyloid a, lactate and IL- 6 markers in liver transplant patients admitted to ED with suspected infection. In Vivo 2017;31:1179-1185. doi: 10.21873/invivo.11187.

[43] Sandkovsky U, Kalil AC, Florescu DF. The use and value of procalcitonin in solid organ transplantation. Clin Transplant 2015;29:689-696. doi: 10. $1111 /$ ctr. 12568.

[44] Lin S, Huang Z, Wang M, Weng Z, Zeng D, Zhang Y, et al. Interleukin-6 as an early diagnostic marker for bacterial sepsis in patients with liver cirrhosis. J Crit Care 2015;30:732-738. doi: 10.1016/j.jcrc.2015.03.031.

[45] Hamed M, Hakim H, El-Masshad N, Eskandere D. Serum procalcitonin and $\mathrm{C}$-reactive protein in prediction of spontaneous bacterial peritonitis. Gastroenterol Hepatol J 2017;1:20-23.

[46] Wang M, Lin S, Zhu Y, Jiang J. The early diagnostic value and cost-effectiveness analysis of common inflammatory markers in cirrhotic patients with infectious fever. Chinese Journal of Infectious Diseases 2016;34:327-331. doi: 10. 3760/cma.j.issn.1000-6680.2016.06.002.

[47] Zant R, Melter M, Knoppke B, Ameres M, Kunkel J. Kinetics of interleukin-6, procalcitonin, and $\mathrm{C}$-reactive protein after pediatric liver transplantation. Transplant Proc 2014;46:3507-3310. doi: 10.1016/j.transproceed.2014. 08.048.

[48] Mallet M, Haq M, Tripon S, Bernard M, Benosman H, Thabut D, et al. Elevated procalcitonin is associated with bacterial infection during acute liver failure only when unrelated to acetaminophen intoxication. Eur J Gastroenterol Hepatol 2017;29:811-816. doi: 10.1097/MEG.0000000000000862.

[49] Schuetz P, Wirz Y, Sager R, Christ-Crain M, Stolz D, Tamm M, et al. Procalcitonin to initiate or discontinue antibiotics in acute respiratory tract infections. Cochrane Database Syst Rev 2017;10:CD007498. doi: 10.1002/14651858. CD007498.pub3 